\title{
Rating of Cables in Unfilled Surface Troughs
}

\author{
J. A. Pilgrim, Member, IEEE, P. L. Lewin, Senior Member, IEEE, S. T. Larsen, F. Waite and \\ D. Payne
}

\begin{abstract}
Cable circuits installed in unfilled troughs must often support high current ratings. To achieve higher ratings in unfilled troughs in the UK, trough lids can be replaced by ventilated grilles, provided that the trough is within a substation site. While several methods exist for rating the traditional covered trough design, no standard method exists for naturally ventilated installations. To examine the possible up-rating available, a coupled numerical model has been created for cable trough installations. Following successful benchmarking tests where the covered trough was modeled, the method has been extended to troughs with full natural ventilation. The results have been compared to commonly used engineering assumptions in order to validate simpler analytical methods. It was found that by allowing full natural ventilation of existing covered troughs, the continuous rating could be increased by as much as $28 \%$.
\end{abstract}

Index Terms-- power cable thermal factors, power transmission

\section{NOMENCLATURE}

internal height of trough $(\mathrm{m})$

thickness of trough cover $(\mathrm{m})$

internal width of trough $(\mathrm{m})$

specific heat capacity $\left(\mathrm{Jkg}^{-1} \mathrm{~K}^{-1}\right)$

Gravitational acceleration $\left(\mathrm{ms}^{-2}\right)$

convective heat transfer coefficient $\left(\mathrm{Wm}^{-2} \mathrm{~K}^{-1}\right)$

IEC 853 preload factor

Emergency rating (A)

Continuous rating (A)

thermal conductivity $\left(\mathrm{Wm}^{-1} \mathrm{~K}^{-1}\right)$

perimeter of trough effective for heat dissipation (m) volumetric heat source $\left(\mathrm{Wm}^{-3}\right)$

heat flux vector $\left(\mathrm{Wm}^{-2}\right)$

conductor ac resistance under preload $\left(\Omega \mathrm{m}^{-1}\right)$

conductor ac resistance at continuous rating $\left(\Omega \mathrm{m}^{-1}\right)$

temperature $(\mathrm{K})$

thermal resistance of trough $\left(\mathrm{KW}^{-1}\right)$

velocity vector

cable heat generation per metre of trough (W)

thermal expansion coefficient $\left(\mathrm{K}^{-1}\right)$

trough air temperature rise above ambient $\left({ }^{\circ} \mathrm{C}\right)$

surface emissivity

Maximum permissible temperature rise above

This work was supported by National Grid plc.

J. A. Pilgrim and P. L. Lewin are with the University of Southampton, Hampshire, SO17 1BJ, U.K. (email: jp2@ecs.soton.ac.uk).

S. T. Larsen is with Southampton Dielectric Consultants Ltd., Southampton, Hampshire, SO53 3HE, U.K.

F. Waite and D. Payne are with National Grid plc, Warwick, CV34 6DA, ambient at end of emergency rating $\left({ }^{\circ} \mathrm{C}\right)$

$\theta_{\mathrm{R}} \quad$ Conductor temperature rise above ambient $\left({ }^{\circ} \mathrm{C}\right)$

$\rho \quad$ density $\left(\mathrm{kg} / \mathrm{m}^{3}\right)$

$\rho_{\mathrm{c}} \quad$ thermal resistivity of trough cover $(\mathrm{K} . \mathrm{m} / \mathrm{W})$

$\rho_{\mathrm{e}} \quad$ thermal resistivity of soil $(\mathrm{K} . \mathrm{m} / \mathrm{W})$

$\sigma \quad$ Stefan-Boltzmann constant

\section{INTRODUCTION}

$T$ HERE are occasions when cable sections installed in unfilled cable troughs in UK substations have the potential to limit the current carrying capability of much longer circuits. For example, parts of the circuit used to link ventilated cable tunnels to transformers or overhead lines often limit the overall rating of the circuit. Traditionally, in the UK, trough installations were fitted with solid concrete covers to maximize the protection of the cable from both solar radiation and mechanical damage. Alternatively troughs could be filled with a low thermal resistivity stabilized backfill. The disadvantage of using solid concrete covers is that the air in the trough is not able to circulate with cooler ambient air, hence attaining much higher temperatures as the heat generated by the cable must be dissipated entirely through the trough walls. This limits the possibility of gaining any increase in the current rating.

In order to maximize the increase of the current ratings of such circuits, it was decided to consider replacement of these concrete covers with ventilated grilles, thus facilitating the movement of air. Several substation troughs have recently been installed with all of the covers being replaced by grilles. This is only possible due to the troughs being entirely within secured substation sites, reducing the possibility of interference. No formal rating method exists for such circuits, however an approach used in the past has been to assume that the cable would be able to support $90 \%$ of the current rating that it would have in free air.

In order to quantify accurately the benefits of converting troughs from the traditional covered design to natural ventilation, this paper develops a rating methodology based on computational fluid dynamics (CFD). The key benefit of this approach is that it allows detailed modeling of the buoyant convection within the troughs, while also accounting for the potential inflow of cooler air. Numerical approaches such as CFD allow much more complex thermal environments to be modeled, however the cost of computation is greater than for analytical models. While such costs may be justified if the required rating is close to the thermal limit of the cable, it is also valuable to form comparisons with analytical methods as part of a benchmarking process. 


\section{EXISTING RATING METHODS}

Although no specific rating method exists for the case of ventilated troughs, there are a number of analytical techniques in use for covered troughs. The most widely used standard rating method is that of IEC 60287 [1]. This method makes the assumption that a cable circuit, installed in a covered unfilled trough, can be rated using the same algorithm as if it were installed in free air, but with an additional air temperature rise, $\Delta \theta_{\mathrm{tr}}$, allocated such that,

$$
\Delta \theta_{\mathrm{tr}}=\frac{\mathrm{W}_{\mathrm{TOT}}}{3 \mathrm{p}}
$$

where $\mathrm{W}_{\text {ТОT }}$ is the heat generated by the cables per metre of trough (W) and $\mathrm{p}$ is the perimeter of the trough which is effective for heat dissipation, i.e. not exposed to solar radiation, $(\mathrm{m})$. In all cases studied, $\mathrm{p}$ is hence the length of the base and two sides of the trough. This equation is empirically derived and does not attempt to take account of the properties of the soil beyond the trough. This assumption has been previously identified in work by Anders [2] as a source of inaccuracy. To develop an improved model, the method derived in [2] removes the need for the calculation of $\Delta \theta_{\mathrm{tr}}$. Instead the thermal resistance of the trough and surrounding ground, $\mathrm{T}_{\mathrm{t}}$, is calculated explicitly,

$$
\mathrm{T}_{\mathrm{t}}=\frac{\rho_{\mathrm{e}}}{0.3907+\mathrm{H}_{\mathrm{c}}+\phi_{\mathrm{b}}}
$$

where $\rho_{\mathrm{e}}$ is the thermal resistivity of the soil $\left(\mathrm{K} . \mathrm{mW}^{-1}\right), \mathrm{H}_{\mathrm{c}}$ is defined as

$$
H_{c}=\frac{H_{s} B \rho_{e}}{a \rho_{c} H_{s}+B}
$$

where $\rho_{c}$ is the thermal resistivity of the trough cover $\left(\mathrm{K}_{\mathrm{mW}}^{-1}\right), \mathrm{B}$ is the internal trough width $(\mathrm{m})$, a is the cover thickness $(\mathrm{m})$ and $\mathrm{H}_{\mathrm{s}}$ is calculated by

$$
H_{s}=2.72 B^{0.75}+5.85 B
$$

for the case of still air, with $\phi_{\mathrm{b}}$ being calculated by

$$
\phi_{b}=2.13\left(\frac{a}{A}+0.05\right)^{-0.39}\left(\frac{B}{A}\right)^{0.065}
$$

with $A$ being defined as the internal height of the trough $(\mathrm{m})$. The value of $T_{t}$ is then added to the conventional value of $T_{4}$ in the IEC 60287 free air calculation to determine the rating for the trough. The method represents an extension of earlier theoretical work by Slaninka, which attempted to represent the thermal resistance of the trough in three parts, namely those posed by the trough lid, base and sides [3]. It is demonstrated in [2] that using this approach removes some of the conservatism inherent in the use of (1). To enable comparison and benchmarking of the CFD models developed within this paper, ratings will also be calculated for the cable circuits in free air (shielded from solar radiation) according to IEC60287.

\section{CFD Modeling TeChNiques}

The numerical models presented within this paper are solved using commercial code based on the finite volume analysis method. This cell based method is more suitable to flow problems than the node based finite element approach. A brief description of the equation system used is given below.

\section{A. Equation System to Model Airflow in a Ventilated Trough}

The equations used to model the buoyant convection in the air are based on the Navier Stokes relationships for fluid flow. Although it is theoretically possible to model the full detail of any flow problem if a sufficiently fine mesh can be used, this is not practical for flows containing turbulent eddies. In reality such intricate levels of detail are not required, meaning that the smallest details can be filtered out through the derivation of the Reynolds Averaged Navier Stokes equations. This approach leaves more variables than defining equations, hence a turbulence model is required to close the equation set [4]. Several different turbulence models exist, however for the buoyant natural convection found in the troughs considered here, the Grashof number is not uniformly high enough to neglect laminar flow. Therefore the turbulence model adopted is the 3 equation transition flow model [5], which introduces the three additional terms:

- $\mathrm{k}_{\mathrm{T}}$, turbulent kinetic energy

- $\mathrm{k}_{\mathrm{L}}$, laminar kinetic energy

- $\omega$, inverse turbulent time scale

\section{B. Heat Transfer}

Perhaps the most significant benefit of using the CFD modeling technique is that it is not necessary to rely on analytical or empirical relationships for convective heat transfer coefficients on the cable and trough surfaces. The standard equation for heat transfer (neglecting viscous heating and pressure work) can be given as

$$
\rho C_{p} \frac{d T}{d t}+\nabla \cdot(-k \nabla T)=Q-\rho C_{p} \boldsymbol{u} \cdot \nabla T
$$

where $\rho$ is the density $\left(\mathrm{kg} \cdot \mathrm{m}^{-3}\right), C_{p}$ the specific heat capacity $\left(\mathrm{Jkg}^{-1} \mathrm{~K}^{-1}\right), T$ the temperature $(\mathrm{K}), k$ is the thermal conductivity $\left(\mathrm{Wm}^{-1} \mathrm{~K}^{-1}\right), \boldsymbol{u}$ is the velocity vector and $Q$ is the volumetric heat source $\left(\mathrm{Wm}^{-3}\right)$. In solid materials $\boldsymbol{u}$ is zero, but in the trough air it can be found via a coupling with the $\mathrm{k}_{\mathrm{T}}-\mathrm{k}_{\mathrm{L}}-\omega$ flow model. The cable surface boundary condition can be given as

$$
\boldsymbol{- n} . \boldsymbol{q}=h\left(T_{f}-T_{s}\right)+\varepsilon \sigma\left(T_{a m b}^{4}-T_{s}^{4}\right)
$$

where $\boldsymbol{n}$ is the normal unit vector to the boundary, $\boldsymbol{q}$ is the heat flux vector, $h$ is the cable surface convective heat transfer coefficient $\left(\mathrm{Wm}^{-2} \mathrm{~K}^{-1}\right), T_{f}$ is the air temperature $(\mathrm{K}), \varepsilon$ is the surface emissivity, $\sigma$ is the Stefan-Boltzmann constant and $T_{a m b}$ is the remote surface temperature (K), representing either a trough wall or another cable in this case. In reality $h$ is not a constant but a function of the local velocity $\boldsymbol{u}$, defined in this case by the law of the wall [6].

In order to model buoyant convection, it is necessary to permit the density of the air to be temperature dependent. A number of approaches can be used, however faster convergence can normally be achieved using the Boussinesq model [7]. This model assumes that the fluid density is constant in all equations except the buoyancy term in the momentum equation. Thus,

$$
\left(\rho-\rho_{0}\right) g \approx-\rho_{0} \beta\left(T-T_{0}\right) g
$$

where $\rho_{0}$ is the (assumed) constant density $\left(\mathrm{kg} \cdot \mathrm{m}^{-3}\right), \mathrm{g}$ is gravitational acceleration at $9.81 \mathrm{~ms}^{-2}, \mathrm{~T}_{0}$ is the operating temperature $(\mathrm{K})$ and $\beta$ is the thermal expansion coefficient $\left(\mathrm{K}^{-1}\right)$. For the assumption to be valid, the following expression must hold:

$$
\beta\left(T-T_{0}\right) \ll 1
$$


Assuming that the product of the temperature difference and the expansion coefficient may not exceed 0.1 , the maximum permissible difference between $\mathrm{T}_{\mathrm{o}}$ and the trough air temperature for (9) to hold would be $29.2^{\circ} \mathrm{C}$, which is an acceptable criterion.

The final step in fully coupling the heat transfer behavior in the trough with that inside the cable is to account for heat transfer by radiation. Modeling of the radiation transfer is achieved with the Discrete Transfer Radiation Model which uses ray tracing to determine the transfer of energy by radiation from one surface to another [8]. The benefit of this approach is that accurate view-factors are calculated based on the whole cable trough geometry.

\section{INSTALLATIONS CONSIDERED}

The following section outlines the parameters used in this study, including the trough and cable geometries.

\section{A. Cable Parameters}

Two cables have been considered in this analysis, both being $2500 \mathrm{~mm}^{2}$ XLPE insulated cables with copper conductors. Cable 1 is a $400 \mathrm{kV}$ circuit with copper wire screen with a laminate sheath of a $0.2 \mathrm{~mm}$ aluminium foil bonded to a polyethylene over-sheath. The conductor resistance is calculated according to [1] with coefficient $k_{s}$ equal to 0.54 and $\mathrm{k}_{\mathrm{p}}$ equal to 0.37 . The sheath loss factor is 0.0519 for the centre phase and 0.0132 and 0.0126 for the outer phases, with a dielectric loss of $3.8 \mathrm{~W} / \mathrm{m}$. Cable 2 is a $275 \mathrm{kV}$ circuit but with a lead sheath, a $\mathrm{k}_{\mathrm{s}}$ coefficient of 0.45 and $\mathrm{k}_{\mathrm{p}}$ coefficient of 0.37 . Its dielectric loss is $1.2 \mathrm{~W} / \mathrm{m}$ with sheath loss coefficients of 0.0612 (centre phase) and 0.016 (outer phases). Table I summarizes both cable designs.

\section{B. Trough Parameters}

The main trough design on which calculations have been undertaken is that shown in Fig. 1, which is equipped with Cable 1. The trough is of concrete construction and the top of the trough is installed flush with the ground surface. The lid of the unventilated trough is constructed of concrete and is $84 \mathrm{~mm}$ thick. The thermal resistivity of the concrete is 1 $\mathrm{K} . \mathrm{m} / \mathrm{W}$ and that of the soil is $1.2 \mathrm{~K} . \mathrm{m} / \mathrm{W}$ prior to drying and 3 $\mathrm{K} . \mathrm{m} / \mathrm{W}$ in the dry state (drying is assumed to occur only within the $50^{\circ} \mathrm{C}$ isotherm). The remote ground temperature is considered to remain constant throughout the year at a value of $12^{\circ} \mathrm{C}$ as discussed in [9], while the ambient air temperatures vary according to the season as follows [10]:

- Summer $30^{\circ} \mathrm{C}$

- Spring/Autumn $20^{\circ} \mathrm{C}$

- Winter $10^{\circ} \mathrm{C}$

These temperatures are weighted to account for incoming solar radiation, however for comparison some calculations have also been undertaken with additional solar gain at the ground surface. For circuit 1 the trough layout is common between ventilation types, with the exception of the trough lids. The lids are constructed of concrete, while the metallic grille design prevents the direct contact of solar radiation on the cable surfaces. For circuit 2 only ventilated troughs are modeled to allow comparison of trends in between the different trough designs, with both 3 phase (Fig. 2) and 2 cable
TABLE I

CABLE CIRCUIT SPECIFICATIONS

\begin{tabular}{|c|c|c|c|c|}
\hline Component & \multicolumn{2}{|c|}{$\begin{array}{c}\text { Outer Diameter } \\
\text { C1 }(\mathrm{mm}) \mathrm{C2}\end{array}$} & Material & $\begin{array}{c}\text { Thermal Conductivity } \\
\left(\mathbf{W} \cdot \mathbf{m}^{-1} \cdot \mathbf{K}^{-1}\right)\end{array}$ \\
\hline Conductor & 62.3 & 65.0 & Copper & 400 \\
\hline $\begin{array}{l}\text { Conductor } \\
\text { Screen }\end{array}$ & 66.7 & 68.6 & $\begin{array}{l}\text { Semicon } \\
\text { XLPE }\end{array}$ & 0.286 \\
\hline Dielectric & 118.7 & 112.6 & XLPE & 0.286 \\
\hline $\begin{array}{l}\text { Insulation } \\
\text { Screen }\end{array}$ & 121.7 & 115.8 & $\begin{array}{l}\text { Semicon } \\
\text { XLPE }\end{array}$ & 0.286 \\
\hline Screen & 129.9 & 120.6 & $\begin{array}{l}\text { Copper } \\
\text { wires/PE }\end{array}$ & 1.253 \\
\hline Lead Sheath & - & 126.4 & Lead & 35.3 \\
\hline Oversheath & 140.5 & 137.6 & $\mathrm{PE}$ & 0.286 \\
\hline
\end{tabular}

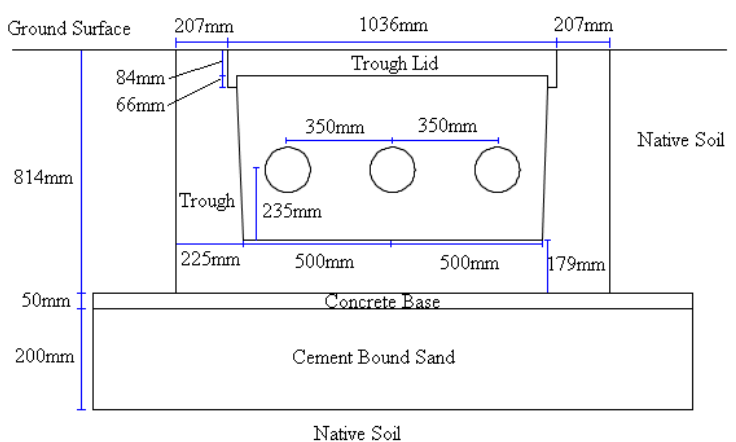

Fig. 1. Geometry of Trough Installation T1 for Circuit 1

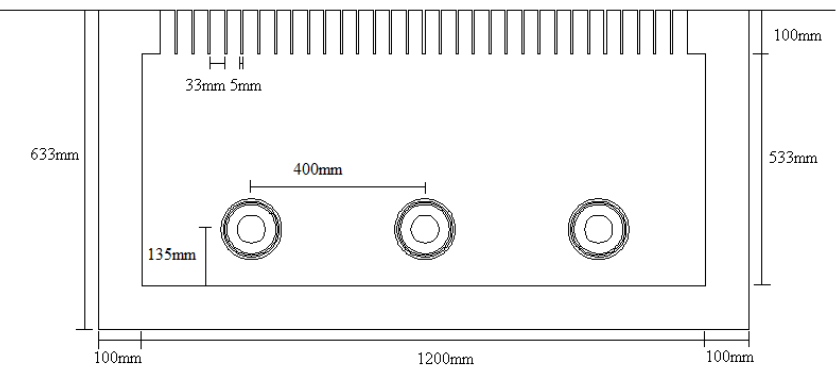

Fig. 2. Geometry of 3 Phase Trough Installation T2A for Circuit 2

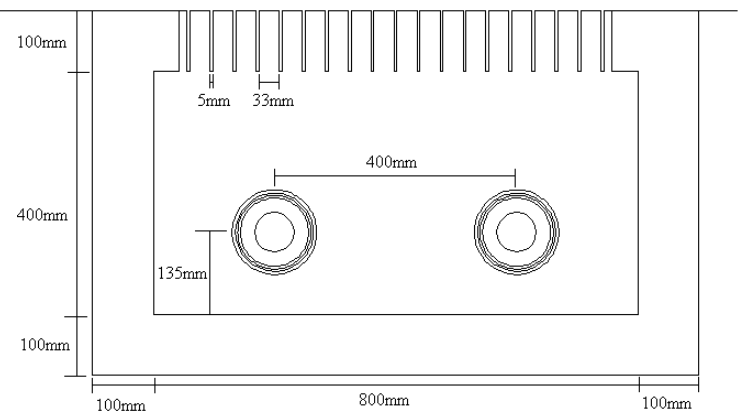

Fig. 3. Geometry of 2 Cable Trough Installation T2B for Circuit 2

(Fig. 3) installations modeled. The T2B configuration occurs on a double circuit where the cables are separated into 3 troughs by phase. For all designs the cables are supported above the trough base by metal brackets, which is common practice on the UK transmission grid.

\section{Covered Trough}

The covered trough model may be modeled using a 2D slice through the geometry illustrated in Fig. 1 given the assumption that the cross section remains constant along the trough length. As a result the longitudinal flow of air (in the direction of the cables) is considered to be zero. A soil region of $20 \mathrm{~m}$ in width and $7 \mathrm{~m}$ in depth is modeled around the trough 
to represent the ground. The boundary condition at $7 \mathrm{~m}$ depth is a constant temperature of $12^{\circ} \mathrm{C}$, with the sides of the model considered insulating. Boundary element meshing is used to increase the element density in the boundary layer zone near to the cable surface. Three groups of boundary conditions are required to represent the trough. The top surface of the lid and the ground surface are convective boundaries with a heat transfer coefficient of $6 \mathrm{~W} / \mathrm{m}^{2} \mathrm{~K}$, appropriate for still air convection. This is an important change to the typical IEC 60287 methodology which forces an isothermal ground surface boundary. Previous work on buried cable systems has proven this to be optimistic for steady state models where the cables are shallow buried [11]. The cable surface boundaries are modeled as a no slip wall condition, with a coupled convective heat transfer boundary for the thermal equations. Boundaries for the trough walls are also modeled on the same principle. Joule and sheath losses are applied to their respective domains as a function of temperature using the full IEC 60287 calculations [1]. The dielectric losses are modeled as a uniformly distributed heat source across the dielectric.

\section{Ventilated Trough}

Much of the design of the ventilated trough model is common with that of the unventilated trough. The treatment of the cable heat sources and the specification of most boundary conditions is identical, with the only changes being those concerning the grille over the trough. The grille itself is assigned a no-slip wall condition for the momentum equations and is considered thermally insulating. The free air space between the metal louvers of the grille is modeled as an ambient pressure inlet boundary at the reference value of 1 atmosphere, with air flowing into the trough assumed to be at the relevant seasonal ambient temperature. Warm air exiting the trough is assumed to diffuse away from the grille and hence may not re-enter the trough.

\section{CONTINUOUS RATINGS}

This section outlines the results derived from the CFD models described in Section $\mathrm{V}$ and forms comparisons with the existing analytical techniques introduced in Section III.

\section{A. Covered Trough}

Solutions for the continuous ratings in the T1 covered trough environment have been calculated using three models, namely the 2D CFD model, the empirical IEC 60287 and the Anders analytical method, as described in (2)-(5). Table II shows a comparison of the continuous ratings obtained from TABLE II

CONTINUOUS RATINGS FOR COVERED TROUGH T1

\begin{tabular}{|l|l|l|l|}
\hline \multicolumn{1}{|c|}{ Season } & $\begin{array}{c}\text { IEC 60287 } \\
\text { Rating (A) }\end{array}$ & $\begin{array}{c}\text { Rating } \\
\text { by [2] (A) }\end{array}$ & $\begin{array}{c}\text { Rating from CFD } \\
\text { Model (A) }\end{array}$ \\
\hline Summer & $2071 \mathrm{~A}$ & $2207 \mathrm{~A}$ & $2139 \mathrm{~A}$ \\
\hline Spring/Autumn & $2257 \mathrm{~A}$ & $2404 \mathrm{~A}$ & $2300 \mathrm{~A}$ \\
\hline Winter & $2430 \mathrm{~A}$ & $2587 \mathrm{~A}$ & $2449 \mathrm{~A}$ \\
\hline
\end{tabular}

TABLE III

AIR TEMPERATURE COMPARISON IN COVERED TROUGH T1

\begin{tabular}{|l|l|l|l|}
\hline \multicolumn{1}{|c|}{ Season } & $\begin{array}{c}\text { CFD } \\
\text { Rating } \\
(\mathbf{A})\end{array}$ & $\begin{array}{c}\text { CFD Mean Trough } \\
\text { Air Temperature } \\
\left({ }^{\circ} \mathbf{C}\right)\end{array}$ & $\begin{array}{c}\text { IEC 60287 Air } \\
\text { Temperature } \\
\left({ }^{\circ} \mathbf{C}\right)\end{array}$ \\
\hline Summer & $2139 \mathrm{~A}$ & $58.3^{\circ} \mathrm{C}$ & $57.4^{\circ} \mathrm{C}$ \\
\hline Spring/Autumn & $2300 \mathrm{~A}$ & $53.3^{\circ} \mathrm{C}$ & $51.3^{\circ} \mathrm{C}$ \\
\hline Winter & $2449 \mathrm{~A}$ & $48.4^{\circ} \mathrm{C}$ & $45.3^{\circ} \mathrm{C}$ \\
\hline
\end{tabular}

TABLE IV

CENTRE Phase HeAt TRANSFER COEFFICIENT COMPARISON IN COVERED TROUGH T1 (REFERENCED TO TROUGH AIR TEMPERATURE)

\begin{tabular}{|l|l|l|c|}
\hline \multicolumn{1}{|c|}{ Season } & $\begin{array}{c}\text { CFD } \\
\text { Rating (A) }\end{array}$ & \multicolumn{2}{|c|}{$\begin{array}{c}\text { Effective Cable Surface Heat } \\
\text { Transfer Coefficient }\left(\mathbf{W} / \mathbf{m}^{2} \mathbf{K}\right)\end{array}$} \\
\cline { 3 - 4 } & & CFD Model & IEC 60287 \\
\hline Summer & $2139 \mathrm{~A}$ & 15.37 & 10.85 \\
\hline Spring/Autumn & $2300 \mathrm{~A}$ & 15.08 & 10.49 \\
\hline Winter & $2449 \mathrm{~A}$ & 14.78 & 10.10 \\
\hline
\end{tabular}

each method across the 3 rating seasons considered. It is clear that IEC 60287 gives the most pessimistic rating in all seasons. This fits the trend seen in the results of [2]. By contrast the ratings calculated by the method of [2] are slightly more optimistic than those obtained from the CFD analysis, by up to $5.6 \%$. The disparity between the results of the CFD model and the IEC 60287 model can be attributed to a number of factors. One obvious point of comparison is the assumed air temperature in the trough, presented in Table III. It is clear that the higher rating given by the CFD model does not come from a lower air temperature, as the IEC 60287 assumed air temperatures are lower by between $1-3^{\circ} \mathrm{C}$ depending on the season. However the data in Table IV shows that the cable surface heat transfer coefficient (comprising contributions from both convection and radiation) is markedly higher for the CFD results. The data for the CFD model is referenced to the mean trough air temperature to allow comparison against IEC 60287, which has only one single ambient temperature specified (that of the air). The reason for the difference in ratings becomes clear when the applicable heat transfer paths are considered. In the CFD model there are effectively two heat sinks present. Heat may either enter the ambient air (via the ground surface or trough lid) or dissipate down through the ground to the remote soil. The remote soil temperature at $7 \mathrm{~m}$ depth is assumed seasonally invariant at $12^{\circ} \mathrm{C}$, hence where the air temperature is $30^{\circ} \mathrm{C}$ in summer the remote ground becomes more important as a heat sink.

The results obtained through the method of [2] are higher than the CFD results for two reasons. Firstly they do not consider the impact of soil drying on the value of T4, a particular concern for the summer season. The normal IEC 60287 partial drying procedure can not be easily applied to this model as the composite T4 value contains contributions from both the air and the ground. The drying phenomena does not apply to the trough air, therefore this would need to be treated separately. A second cause is that the ground surface above the trough is considered to be isothermal at the ambient air temperature. Fig. 4 demonstrates that this would not be the case, hence the assumption of an isothermal ground surface

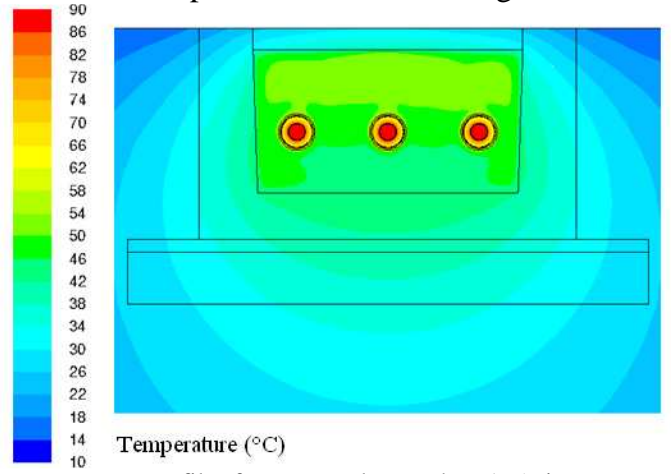

Fig. 4. Temperature profile for covered trough $\mathrm{T} 1$ (winter parameters), continuous rating of $2449 \mathrm{~A}$ 


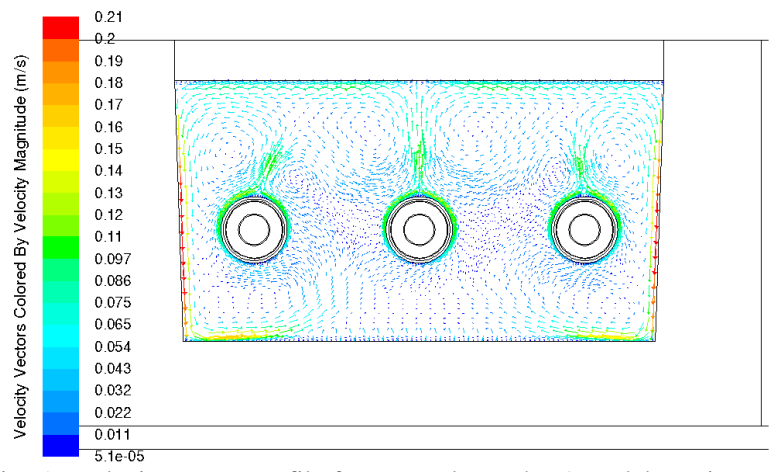

Fig. 5. Velocity vector profile for covered trough $\mathrm{T} 1$ model at winter season continuous rating of $2449 \mathrm{~A}$

could lead to the heat transfer through the trough lid being overestimated. Fig. 5 illustrates the air velocity profile during the winter season. The impact of buoyant convection can be clearly seen above and around the cable surfaces, where the air is moving much more quickly. The temperature difference across the air volume is relatively small at around $10^{\circ} \mathrm{C}$, with the cooler air below the cables as expected.

\section{B. Ventilated Trough}

The work presented in Section VI A for the covered trough design demonstrates that CFD models compare well to existing analytical techniques. This provides confidence that the technique will be suitable for the rating of ventilated troughs, for which no analytical solution is yet available. Results are calculated for the three seasons using the same parameters as for the $\mathrm{T} 1$ covered trough model, with the results displayed in Table $\mathrm{V}$. A comparison to the standard IEC 60287 free air rating is given for the solar shielded case. IEC60287 does not contain a direct method for rating such an installation, with [2] also being inapplicable in this instance as it does not cater for the circulation of air into/out of the trough. From Table V, it is apparent that the introduction of natural ventilation has allowed a significant increase in continuous current rating, with the biggest increase being $28.5 \%$ for the winter season. However the ratings are still below those expected from the same cable circuit installed in free air, as given by IEC 60287 . Such behavior is expected as the trough air temperature will exceed that assumed in the free air model. A key point to note is that the CFD model predicts more optimistic ratings than the existing "rule of thumb" of $90 \%$ of the IEC free air rating. Instead the values correspond to around $96 \%$ of the free air rating. Table VII demonstrates similar trends for the Trough $2 \mathrm{~A} / 2 \mathrm{~B}$ specifications, where the rating obtained for the $2 \mathrm{~B}$ configuration is marginally lower than the three phase trough $2 \mathrm{~A}$. This can be attributed to the greater volume of air present in the trough per active cable in the T2A design. The cause for the rating increase over the unventilated trough design is mainly the reduction in air temperature, as evidenced by the data of Table VI. The mean

TABLE V

CONTINUOUS RATINGS FOR VENTILATED TROUGH T1

\begin{tabular}{|l|l|l|l|}
\hline \multicolumn{1}{|c|}{ Season } & $\begin{array}{c}\text { IEC 60287 Free } \\
\text { Air Rating (A) }\end{array}$ & $\begin{array}{c}\text { Rating by } \\
\text { CFD (A) }\end{array}$ & $\begin{array}{c}\text { Increase on } \\
\text { Covered Trough } \\
\text { CFD Rating (\%) }\end{array}$ \\
\hline Summer & $2774 \mathrm{~A}$ & $2686 \mathrm{~A}$ & $25.5 \%$ \\
\hline Spring/Autumn & $3024 \mathrm{~A}$ & $2946 \mathrm{~A}$ & $28.1 \%$ \\
\hline Winter & $3257 \mathrm{~A}$ & $3148 \mathrm{~A}$ & $28.5 \%$ \\
\hline
\end{tabular}

TABLE VI

AIR TEMPERATURE COMPARISON IN VENTILATED TROUGH T1

\begin{tabular}{|l|l|l|l|}
\hline \multicolumn{1}{|c|}{ Season } & $\begin{array}{c}\text { CFD } \\
\text { Rating } \\
(\mathbf{A})\end{array}$ & $\begin{array}{c}\text { CFD Mean Trough } \\
\text { Air Temperature } \\
\left({ }^{\circ} \mathbf{C}\right)\end{array}$ & $\begin{array}{c}\text { IEC 60287 Air } \\
\text { Temperature } \\
\left({ }^{\circ} \mathbf{C}\right)\end{array}$ \\
\hline Summer & $2686 \mathrm{~A}$ & $35.8^{\circ} \mathrm{C}$ & $30^{\circ} \mathrm{C}$ \\
\hline Spring/Autumn & $2946 \mathrm{~A}$ & $25.9^{\circ} \mathrm{C}$ & $20^{\circ} \mathrm{C}$ \\
\hline Winter & $3148 \mathrm{~A}$ & $16.0^{\circ} \mathrm{C}$ & $10^{\circ} \mathrm{C}$ \\
\hline
\end{tabular}

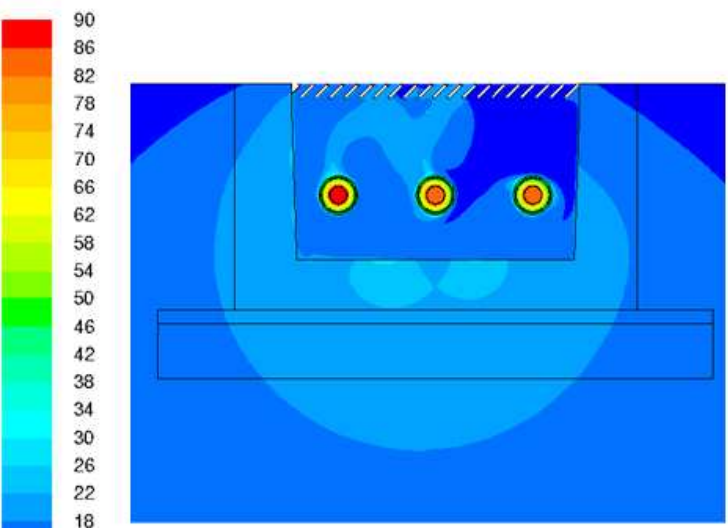

Temperature $\left({ }^{\circ} \mathrm{C}\right)$

Fig. 6. Temperature profile for ventilated trough model $\mathrm{T} 1$ at winter season continuous rating of $3148 \mathrm{~A}$

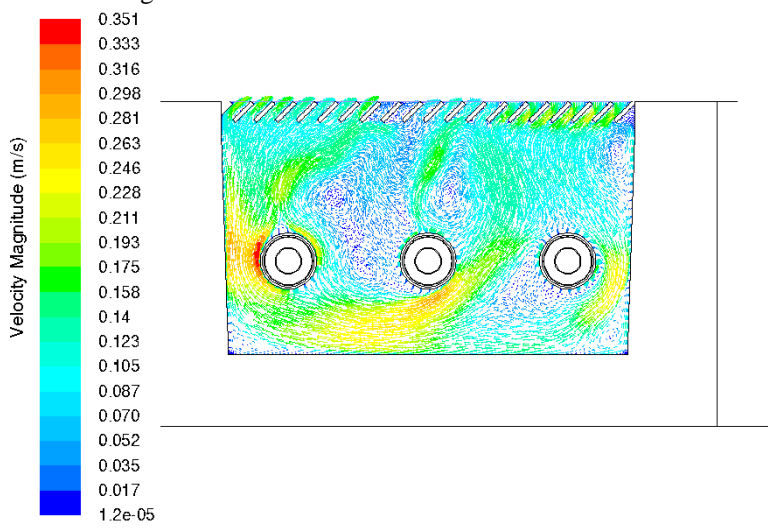

Fig. 7. Velocity vector profile for ventilated trough $\mathrm{T} 1$ model at winter season continuous rating of $3148 \mathrm{~A}$

TABLE VII

AIR TEMPERATURE COMPARISON IN VENTILATED TROUGH T2A AND T2B

\begin{tabular}{|c|c|c|c|c|c|}
\hline \multirow[t]{2}{*}{ Season } & \multicolumn{2}{|c|}{$\begin{array}{l}\text { CFD Rating } \\
\text { (A) }\end{array}$} & \multirow{2}{*}{\multicolumn{2}{|c|}{$\begin{array}{c}\text { CFD Mean } \\
\text { Trough Air } \\
\text { Temperature }\left({ }^{\circ} \mathbf{C}\right) \\
\end{array}$}} & \multirow{2}{*}{$\begin{array}{c}\text { IEC 60287 } \\
\text { Free Air } \\
\text { Rating [A] }\end{array}$} \\
\hline & $\mathbf{T 2 A}$ & T2B & & & \\
\hline Summer & $2902 \mathrm{~A}$ & $2877 \mathrm{~A}$ & $32.3^{\circ} \mathrm{C}$ & $35.3^{\circ} \mathrm{C}$ & $3006 \mathrm{~A}$ \\
\hline Spring/Autumn & $3168 \mathrm{~A}$ & $3127 \mathrm{~A}$ & $22.4^{\circ} \mathrm{C}$ & $25.5^{\circ} \mathrm{C}$ & $3274 \mathrm{~A}$ \\
\hline Winter & $3401 \mathrm{~A}$ & $3398 \mathrm{~A}$ & $12.6^{\circ} \mathrm{C}$ & $15.1^{\circ} \mathrm{C}$ & $3523 \mathrm{~A}$ \\
\hline
\end{tabular}

air temperature in the $\mathrm{T} 1$ trough is seen to exceed the ambient temperature by approximately $6^{\circ} \mathrm{C}$. Table VII shows similar values for $\mathrm{T} 2 \mathrm{~B}$, although the air temperature increase for the T2A trough is lower. Fig. 6 illustrates that in the T1 trough the air temperature distribution is slightly uneven due to the direction of air circulation, visible from the velocity vector plot in Fig. 6. This particular pattern is initiated due to the shape of the grille installed (which has the dual purpose of preventing direct sunlight from entering the trough).

The effective heat transfer coefficient data presented in Table VIII shows values from the CFD models which are much closer to those from IEC 60287. Analysis of the model data for the winter seasons shows that the vast majority of the heat generated by the cables is removed from the trough by 
TABLE VIII

CEnTRe Phase Heat Transfer CoEFFICIENT COMPARISON IN T1

VENTILATED TROUGH (REFERENCED TO TROUGH AIR TEMPERATURE)

\begin{tabular}{|l|l|l|l|}
\hline \multicolumn{1}{|c|}{ Season } & $\begin{array}{c}\text { CFD } \\
\text { Rating (A) }\end{array}$ & \multicolumn{2}{|c|}{$\begin{array}{c}\text { Effective Cable Surface Heat } \\
\text { Transfer Coefficient }\left(\mathbf{W} / \mathbf{m}^{2} \mathbf{K}\right)\end{array}$} \\
\cline { 3 - 4 } & & CFD Model & IEC 60287 Free Air \\
\hline Summer & $2686 \mathrm{~A}$ & 11.99 & 10.85 \\
\hline Spring/Autumn & $2946 \mathrm{~A}$ & 10.98 & 10.49 \\
\hline Winter & $3148 \mathrm{~A}$ & 10.70 & 10.10 \\
\hline \multicolumn{3}{|c}{ TABLE IX }
\end{tabular}

AIR TEMPERATURE COMPARISON IN T1 VENTILATED TROUGH

\begin{tabular}{|l|l|l|}
\hline \multicolumn{1}{|c|}{ Season } & $\begin{array}{c}\text { CFD Ventilated } \\
\text { Trough Rating } \\
(\mathbf{A})\end{array}$ & $\begin{array}{c}\text { IEC 60287 Free Air Rating } \\
\text { (Based on trough air } \\
\text { temperatures, A) }\end{array}$ \\
\hline Summer & $2686 \mathrm{~A}$ & $2620 \mathrm{~A}$ \\
\hline Spring/Autumn & $2946 \mathrm{~A}$ & $2879 \mathrm{~A}$ \\
\hline Winter & $3148 \mathrm{~A}$ & $3119 \mathrm{~A}$ \\
\hline
\end{tabular}

the exchange of air in the ventilated trough case. A total of $92.7 \%$ of the total heat transfer occurs in this manner, with the remainder being transferred to the remote ground through the walls of the trough. By comparison, for the unventilated trough model only $53.3 \%$ of the generated heat exits the trough through the concrete lid.

Based on this information, it would be expected that if the trough air temperature from the CFD model was used in the IEC 60287 rating calculation, the ratings obtained should be slightly below those from the CFD model. This would be because the heat transfer path through the trough walls to the soil is neglected in IEC60287. Examining the results in Table IX, this hypothesis appears to be valid with the difference in the warmer seasons being around $2.5 \%$. The results of the two models are very similar in the winter season as the remote ground temperature at $12^{\circ} \mathrm{C}$ is very close to the air temperature of $16^{\circ} \mathrm{C}$, hence the total heat transferred is small.

\section{Sensitivity Analysis}

In order to further illustrate the benefits of using naturally ventilated troughs, a comparative sensitivity analysis has been undertaken to the key variables.

\section{1) Solar Radiation}

The air temperature values assumed in [10] are weighted to include the effects of solar radiation, however it is possible to add an additional incoming heat flux to the ground surface/trough lid boundaries to allow solar radiation to be modeled directly. This may be of value in the winter season at certain locations, where the air temperature may be low but the troughs may still be exposed to significant solar radiation. For the covered T1 trough model, the addition of either 100W $\mathrm{m}^{-2}$ or $200 \mathrm{Wm}^{-2}$ of solar heating (with a ground surface emissivity of 0.8 ) leads to continuous rating decreases of $7.7 \%$ and $16.0 \%$ respectively, due to higher ground surface temperatures and reduced heat transfer through the trough lid. However for the T2A ventilated trough model, the effects are only $1.3 \%$ and $3.0 \%$ respectively. Although the impact on ground surface temperatures away from the trough is the same, because more than $90 \%$ of the heat transfer is via air circulation the rating impact is small as no solar radiation passes the grille into the trough.

\section{2) Remote Ground Temperature}

As both covered and ventilated troughs are so close to the ground surface, the impact of the remote ground temperature is very small. Taking the covered trough as an example, a $2^{\circ} \mathrm{C}$ increase in the remote ground temperature to $14^{\circ} \mathrm{C}$ produces only a $0.2^{\circ} \mathrm{C}$ change in conductor temperature in the summer season. Similarly small effects are seen for the ventilated design, as would be expected given the low sensitivity to ground surface temperature already noted.

\section{3) Ground Surface Convective Coefficient}

As with previous models which specify a non-isothermal ground surface, the rating obtained will naturally be sensitive to the assumed convective heat transfer coefficient on this surface [11]. For the T1 covered trough, increasing the convective heat transfer coefficient from $6 \mathrm{Wm}^{-2} \mathrm{~K}^{-1}$ to $10.6 \mathrm{Wm}^{-2} \mathrm{~K}^{-1}$ (equivalent to $1 \mathrm{~ms}^{-1}$ wind speed) for the summer season reduces the conductor temperature by $4.0^{\circ} \mathrm{C}$, while a further $1.7^{\circ} \mathrm{C}$ reduction is seen if $2 \mathrm{~ms}^{-1}$ is assumed. Given that the steady state nature of the models, it is important to select a value representative of the average conditions at site.

\section{4) Soil Thermal Conductivity}

For directly buried cables, the rating is very sensitive to the soil thermal conductivity. Again the T1 covered trough rating is quite sensitive to the assumed soil thermal conductivity, with an increase from $0.5-1 \mathrm{~W} . \mathrm{m}^{-1} \mathrm{~K}^{-1}$ leading to a reduction in conductor temperature of $4.1^{\circ} \mathrm{C}$ for the summer season. However the impact on the temperatures in the ventilated trough is negligible for the same variation in $k$, again due to the dominance of heat transfer via air circulation rather than conduction through the trough to the surrounding soil.

\section{EMERGENCY RATING CALCULATIONS}

Within the UK transmission network, emergency ratings are defined as the highest current which can be applied to a cable circuit for a finite duration (for instance 6 hours), given prior operation of that cable circuit at a defined percentage of its continuous rating (preload). Although no rating method exists for ventilated troughs, the nearest comparator for cables in air is that of IEC 853 [12], where the short term emergency rating can be calculated by

$$
I_{2}=I_{R}\left\{\frac{h_{1}^{2} R_{1}}{R_{\max }}+\frac{\left(\frac{R_{R}}{R_{\max }}\right)\left(\frac{\theta_{\max }}{\theta_{r(\infty)}}-h_{1}^{2}\left[\frac{R_{1}}{R_{r}}\right]\right)}{\theta_{R}(t) / \theta_{R}(\infty)}\right\}
$$

Where $I_{2}(A)$ is the emergency rating over the duration $t$ (hours), $\mathrm{I}_{\mathrm{R}}$ is the steady state loading (calculated from IEC 60287), $h_{1}$ is the preload factor between 0 and 1 (where 1 is the continuous load $\left.I_{R}\right), R_{1}$ is the ac resistance of the conductor under preload $\left(\Omega \mathrm{m}^{-1}\right), \mathrm{R}_{\max }$ is the ac resistance at the end of the emergency rating period $\left(\Omega \mathrm{m}^{-1}\right), \mathrm{R}_{\mathrm{R}}$ is the ac resistance under continuous rating $\left(\Omega \mathrm{m}^{-1}\right), \theta_{\max }$ is the maximum permissible temperature rise above ambient at the end of emergency loading $\left({ }^{\circ} \mathrm{C}\right), \theta_{\mathrm{R}(\mathrm{t})}$ is the conductor temperature rise $\left({ }^{\circ} \mathrm{C}\right)$ above ambient after application of $\mathrm{I}_{\mathrm{R}}$ for time $\mathrm{t}$ and $\theta_{\mathrm{R}(\infty)}$ is the value of $\theta_{\mathrm{R}}$ in steady state.

\section{A. Covered Trough}

For unventilated troughs there is some difficulty in handling the air temperature rise in the trough, calculated by (1). A suitable initial value can be determined, however this forces the assumption that there is no change in $\Delta \theta_{\text {tr }}$ over the duration of the emergency rating. While such an assumption could be viable over a short emergency rating period, over longer rating periods it would be expected to lead to an over-estimate of the 
true rating. To explore the potential for this to happen, a transient version of the unventilated T1 trough CFD model has been solved to obtain the seasonal 6 hour ratings. The data is compared against the results of the conventional IEC 853 analysis in Table $\mathrm{X}$. For the IEC 853 data it is assumed that the value of $\Delta \theta_{\text {tr }}$ remains constant at the preload value.

A number of trends are clear from the data in Table X. At higher preloads, the IEC 853 calculation under-estimates the six hour rating when compared to the CFD model. This is in part due to the fact that the CFD analysis gives a higher continuous rating, meaning that in the CFD model the initial cable temperature is lower. However as the preload decreases, the agreement between the two models improves. This can be more easily seen in Fig. 8, which compares the data in terms of preload magnitudes. Under the emergency rating case, it is clear that the more realistic dual temperature heat sink modeled by the CFD model has a greater effect. This is particularly true in summer, where the temperature difference between the two heat sinks is greater. A secondary contribution comes from the fully temperature dependent modeling of cable losses in the CFD model, rather than the approximation used in IEC 853.

\section{B. Ventilated Trough}

The analysis presented in the previous sections shows that the CFD modeling approach gives higher six hour emergency ratings for the unventilated trough than the existing IEC 853 analysis, despite the failure of the IEC method to account for the increase in trough air temperature over the rating duration. Table XI and Fig. 9 illustrate the six hour rating results obtained from the ventilated trough CFD model. It is clear the ventilated trough offers greatly improved six hour ratings, especially for the higher pre-fault loads. This occurs through the trough air temperature at the start of the preload period

TABLE X

SiX Hour EMERGENCY RATINGS FOR COVERED T1 CABLE TROUGH

\begin{tabular}{|c|c|c|c|c|c|c|}
\hline \multirow{2}{*}{ Preload (\%) } & \multicolumn{6}{|c|}{ 6hr Emergency Rating } \\
\cline { 2 - 7 } & \multicolumn{2}{|c|}{ Summer } & \multicolumn{2}{c|}{ Spring/Autumn } & \multicolumn{2}{c|}{ Winter } \\
\cline { 2 - 7 } & CFD & IEC853 & CFD & IEC853 & CFD & IEC853 \\
\hline $85 \%$ & $2459 \mathrm{~A}$ & $2224 \mathrm{~A}$ & $2635 \mathrm{~A}$ & $2425 \mathrm{~A}$ & $2825 \mathrm{~A}$ & $2612 \mathrm{~A}$ \\
\hline $75 \%$ & $2639 \mathrm{~A}$ & $2368 \mathrm{~A}$ & $2825 \mathrm{~A}$ & $2583 \mathrm{~A}$ & $3013 \mathrm{~A}$ & $2783 \mathrm{~A}$ \\
\hline $60 \%$ & $2812 \mathrm{~A}$ & $2587 \mathrm{~A}$ & $3031 \mathrm{~A}$ & $2821 \mathrm{~A}$ & $3235 \mathrm{~A}$ & $3040 \mathrm{~A}$ \\
\hline $30 \%$ & $3044 \mathrm{~A}$ & $2915 \mathrm{~A}$ & $3278 \mathrm{~A}$ & $3175 \mathrm{~A}$ & $3485 \mathrm{~A}$ & $3417 \mathrm{~A}$ \\
\hline $0 \%$ & $3119 \mathrm{~A}$ & $3029 \mathrm{~A}$ & $3359 \mathrm{~A}$ & $3297 \mathrm{~A}$ & $3568 \mathrm{~A}$ & $3545 \mathrm{~A}$ \\
\hline
\end{tabular}

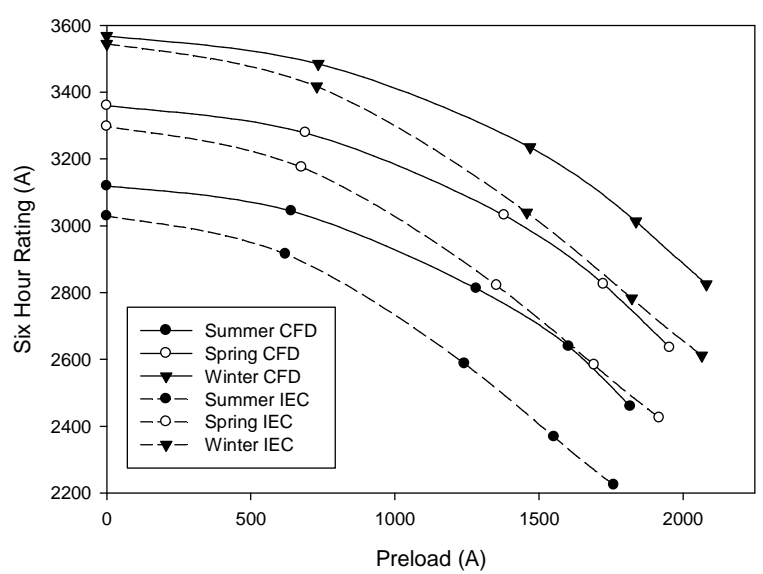

Fig. 8. Comparison of CFD and IEC 853 derived seasonal six hour emergency ratings for the unventilated trough design
TABLE XI

SiX Hour EMERGENCY RATINGS FOR Ventilated T1 CABLE TROUGH

\begin{tabular}{|c|c|c|c|c|c|c|}
\hline \multirow{2}{*}{ Preload (\%) } & \multicolumn{6}{|c|}{ 6hr Emergency Rating $(\mathrm{A})$} \\
\cline { 2 - 7 } & \multicolumn{2}{|c|}{ Summer } & \multicolumn{2}{c|}{ Spring/Autumn } & \multicolumn{2}{c|}{ Winter } \\
\cline { 2 - 7 } & CFD & IEC* & CFD & IEC* & CFD & IEC* \\
\hline $85 \%$ & $2871 \mathrm{~A}$ & $3280 \mathrm{~A}$ & $3119 \mathrm{~A}$ & $3552 \mathrm{~A}$ & $3328 \mathrm{~A}$ & $3806 \mathrm{~A}$ \\
\hline $75 \%$ & $2917 \mathrm{~A}$ & $3328 \mathrm{~A}$ & $3168 \mathrm{~A}$ & $3603 \mathrm{~A}$ & $3380 \mathrm{~A}$ & $3859 \mathrm{~A}$ \\
\hline $60 \%$ & $3018 \mathrm{~A}$ & $3388 \mathrm{~A}$ & $3275 \mathrm{~A}$ & $3666 \mathrm{~A}$ & $3500 \mathrm{~A}$ & $3925 \mathrm{~A}$ \\
\hline $30 \%$ & $3156 \mathrm{~A}$ & $3467 \mathrm{~A}$ & $3407 \mathrm{~A}$ & $3749 \mathrm{~A}$ & $3650 \mathrm{~A}$ & $4012 \mathrm{~A}$ \\
\hline $0 \%$ & $3200 \mathrm{~A}$ & $3492 \mathrm{~A}$ & $3457 \mathrm{~A}$ & $3776 \mathrm{~A}$ & $3706 \mathrm{~A}$ & $4041 \mathrm{~A}$ \\
\hline
\end{tabular}

*IEC 853 rating for cable in free air

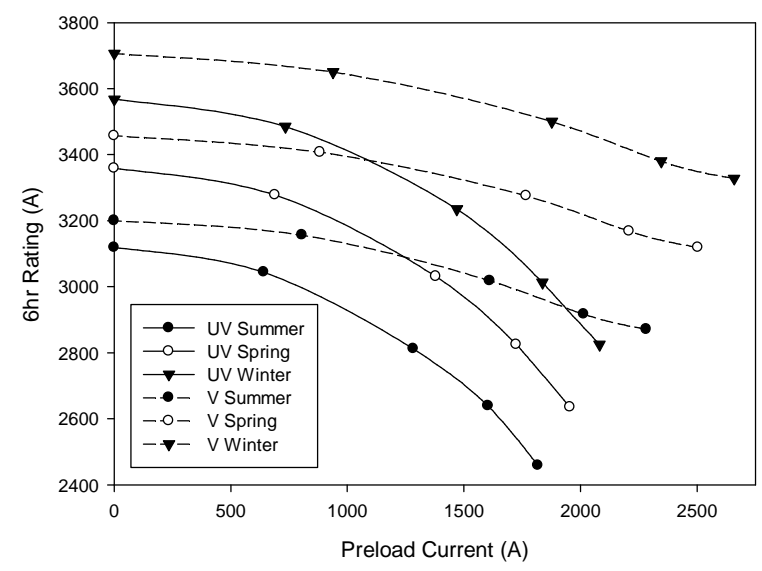

Fig. 9. Comparison of seasonal six hour emergency ratings against pre-fault load for both trough designs (UV=unventilated trough, V=ventilated trough).

being significantly lower than in the unventilated case. However the data in Table XI also demonstrates that the emergency ratings for the ventilated trough are vastly lower than the IEC 853 free air emergency rating for the same cable, due to the CFD model accounting for the increase in trough air temperature. Despite this, the improved emergency rating performance available from moving to ventilated troughs is high compared to the relatively low capital spend required.

\section{MODEL EvaluATION}

The 2D CFD models presented in this paper are relatively easy to build and can be solved in an acceptable length of computation time (circa 15 minutes). However they suffer the disadvantage of requiring a bespoke model and mesh for each new trough or cable geometry, while such parameters can be changed with ease in an analytical analysis such as IEC 60287. For conventional unventilated troughs the use of either the IEC approach or that of [2] is likely to be sufficient and a CFD analysis would not be worthwhile in most cases.

For the ventilated troughs where no direct analytical calculation exists at present, the use of CFD analyses is valuable. However, as the route length installed in troughs is often short and other sections may prove more thermally limiting, assuming a baseline capability of $90 \%$ of the IEC 60287 free air rating appears a viable, if potentially conservative option. In the longer term it would appear more computationally efficient to devise a deterministic analytical method, the research for which is already underway.

\section{Conclusions}

This paper has presented a method for the calculation of cable ratings in air filled troughs using computational fluid dynamics analysis. Comparison with existing analytical 
methods for unventilated troughs has shown that the IEC 60287 method can give conservative ratings through not explicitly modeling the thermal effects of the ground outside the trough. The analytical calculation presented in [2] is less conservative than the IEC 60287 method, however it can give ratings in excess of those found using CFD modeling.

Application of the CFD modeling technique to the case of naturally ventilated troughs has shown that increases in the continuous current rating of up to $28 \%$ are feasible. This is due to a considerable reduction in the air temperature inside the trough through the circulation induced by the buoyant convection of air around the cables. Where trough lids can be safely replaced by ventilated grilles, for instance inside substation compounds, the use of such methods removes the need for forced ventilation, minimizing ongoing costs and reducing availability constraints. While no formal analytical rating method exists, it is recommended that the rating is assumed to be $90 \%$ of the IEC Free Air (Solar Shielded) continuous rating, provided that the grille design employed prevents solar radiation from entering the trough. Research is ongoing to derive an analytical or empirical equation to avoid the need to undertake CFD analysis.

Analysis of the commonly applied 6 hour emergency rating for unventilated troughs has shown that despite the IEC 853 calculation failing to consider the change in air temperature over the course of the six hours it gives more conservative results than the CFD analysis. This can be attributed to the higher rate of heat transfer through the ground in the CFD analysis. The increase in emergency rating gained by moving to ventilated troughs is only around $100 \mathrm{~A}$ for the lowest preloads, however vast increases in six hour ratings were calculated for preloads greater than 1000A. Where it is possible to convert substation trough sections to natural ventilation, the operational rating benefits are high when considered against the required capital spend. However some additional maintenance may be required to ensure the troughs and grilles remain clear of leaves and debris.

\section{REFERENCES}

[1] International Electrotechnical Commission, "Electric Cables Calculation of the current rating BS IEC 60287 -1 -1:2006" British Standards Institution.

[2] G. J. Anders, M. Coates and M. Chabaan, "Ampacity Calculations for cables in shallow troughs," IEEE Trans. Power Delivery, vol. 25, no. 4, pp 2064-2072, 2010.

[3] P. Slaninka, "Thermal resistance of a cable channel," Bulli. Vuki., vol. 18, no. 5, pp 212-221. 1965.

[4] J. H. Ferziger and M. Perić, Computational Methods for Fluid Dynamics, Springer, 2002.

[5] D. K. Walters and D Cokljat, "A three-equation eddy-viscosity model for Reynolds averaged navier stokes simulations of transitional flows," $J$ Fluids Eng., vol. 130, no. 12, Dec. 2008.

[6] B. E. Launder and D. B. Spalding, "The numerical computation of turbulent flows," Computer methods in applied mechanics and engineering, vol. 3, pp269-289, 1974.

[7] C. Long, Essential Heat Transfer, England:Pearson, 1999, p. 112.

[8] F. C. Lockwood and N. G. Shah, "A new radiation solution method for incorporation in general combustion prediction procedures," in Proceedings of the $18^{\text {th }}$ International Symposium on Combustion, pp1405-1413. 1981.

[9] P. L. Lewin, J. E. Theed, A. E. Davies and S. T. Larsen, "Methods for rating power cables buried in surface troughs," IEE Proceedings:
Generation, Transmission and Distribution, vol. 146, no. 4, 1999. pp360-364.

[10] F. Waite, "National Grid Technical Standard 2.0.5 - Cable Systems", National Grid, Warwick, UK, NGTS2.05, December 2010.

[11] D. J. Swaffield, P. L. Lewin and S. J. Sutton, "Methods for rating directly buried high voltage cable circuits," IET Generation, Transmission and Distribution, vol. 2, no.3, pp393-401, 2008.

[12] International Electrotechnical Commission, "Calculation of the cyclic and emergency current rating of cables - Part 2: Cyclic rating of cables greater than 18/30 (36) $\mathrm{kV}$ and emergency ratings for cables of all voltages. IEC 60853-2:1989-07. International Electrotechnical Commission.

\section{BIOGRAPHIES}

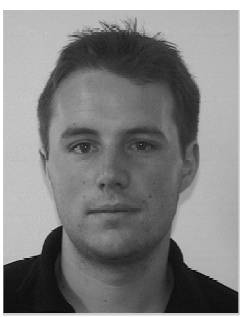

James A. Pilgrim (M'09) received the Bachelors degree in electrical engineering from the School of Electronics and Computer Science at the University of Southampton in 2007. He joined the staff of the University of Southampton in 2007 as a Research Assistant and part time $\mathrm{PhD}$ student. He was awarded a doctoral degree in electrical engineering in July 2011. His research interests include high voltage cable systems and FEA modelling techniques. He is a member of both the IEEE DEIS

and PES societies.

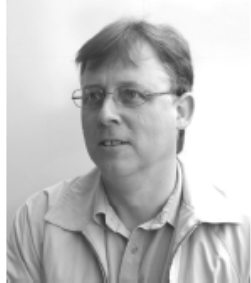

Paul L. Lewin (M'05, SM'08) was born in Ilford, Essex in 1964. He received the B.Sc. (Hons) and Ph.D. degrees in electrical engineering from the University of Southampton, UK in 1986 and 1994, respectively. He joined the academic staff of the University in 1989 and at present is the Professor of Electrical Power Engineering in the Faculty of Physical and Applied Sciences. His research interests include condition monitoring of $\mathrm{HV}$ cables and plant, surface charge measurement, HV insulation/dielectric materials and applied signal processing. Since 1996 he has published over 320 refereed conference and journal papers in these research areas. $\mathrm{He}$ is a Chartered Engineer and a Fellow of the Institution of Engineering and Technology, UK. $\mathrm{He}$ is the manager of the Tony Davies High Voltage Laboratory at the University of Southampton. He was the general chair of the IEEE International Conference on Solid Dielectrics 2007 held in Winchester, Hampshire, UK and is currently secretary of the IEEE Dielectrics and Electrical Insulation Society and an associate editor of the IEEE Trans. DEI.

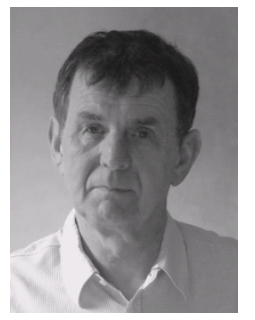

Steffen T. Larsen was born in Copenhagen, Denmark in 1948, and has lived in England since 1956. He received a B.Sc. (Hons) in Physics from the University of East Anglia UK in 1975 and worked as a research officer at the Central Electricity Research Laboratories (CERL) in Leatherhead UK from 1975 to 1990. He joined The National Grid company UK in 1990 where he was responsible for providing cable rating expertise for existing and planned cable systems. He joined Southampton Dielectric Consultants in 2002 where he continues to provide cable rating advice. He is a Chartered Engineer and a Member of the IET.

David Payne joined National Grid in 1992, having previously worked in the engineering industry since 1968. He gained an Open University BSc (Hons) degree in 1993. David has held several posts within National Grid including Drawing Office Team Leader, System Development Engineer, and Analyst involved with Seven Year Statement, Grid Code and Security and Quality of Supply Standards. His current role is Thermal Ratings Engineer with a particular focus on EHV cable ratings.

Francis Waite received the Bachelors degree in electrical and electronic engineering from Loughborough University in 1990. He then worked at Pirelli Cables and Systems until he joined National Grid in 1999. His current role is Asset Policy Engineer with a particular focus on EHV cable systems. He is a Chartered Engineer and a Member of the Institution of Engineering and Technology. 